\title{
Seasonal forecasts of the SINTEX-F coupled model applied to maize yield and streamflow estimates over north-eastern South Africa
}

J Malherbe (Corresponding Author)

Agricultural Research Council, South Africa

$+27824147006$

$+27123231157$

Johan@arc.agric.za

Dr WA Landman

CSIR Natural Resources and the Environment: Climate Studies and Modelling, Pretoria, South Africa

Department of Geography, Geoinformatics and Meteorology, University of Pretoria, Pretoria, South Africa

C Olivier

South African Weather Service, South Africa

Dr H Sakuma

Research Institute for Global Change (RIGC) of the Japan Agency for Marine-Earth Science and Technology (JAMSTEC), Japan

Dr J-J Luo

Centre for Australian Weather and Climate Research, Australia

\begin{abstract}
Forecasts of a Global Coupled Model for Austral summer with a 1-month lead are downscaled to end-of-season maize yields and accumulated streamflow over the Limpopo Province and adjacent districts in northeastern South Africa through application of a MOS (Model Output Statistics) approach applied over a 28-year period. Promising results, based
\end{abstract}


on the hindcasts of the Global Models and historically observed yield and streamflow data, suggest potential for a commodity-orientated forecast system for application in agriculture in an operational environment. It also serves as a baseline study for inclusion of sophisticated crop or runoff models utilising GCM output data towards estimating potential yields and streamflows in the region.

\section{Introduction}

Seasonal forecasts are expected to capacitate the farming community to adapt during periods of climate stress and variability given the effective dissemination and use of the information (Klopper et al., 2006). The application of these forecasts in Agriculture have been promoted during the past few years with promising user responses in several countries including Australia (Hayman et al., 2007) and South and southern Africa (Klopper, 1999, O'Brien and Vogel, 2003,Vogel and O'Brien, 2006). However, factors limiting the usefulness of forecasts include poor dissemination of information, poor communication between key role players in agriculture and producers of long range forecasts as well as difficulty in interpreting seasonal forecast information not necessarily packaged into an understandable format for the end user (Archer, 2003, Vogel and O'Brien, 2006, Ziervogel, 2004). A need therefore arises for presenting seasonal forecast information for agriculture as the probabilistic forecast of agricultural crop yield, updated through a growing season, having the potential to benefit a range of decision makers in climate risk management interventions (Hansen et al., 2011).

Current seasonal forecast models rely on the modelling of global teleconnections in response to large scale phenomena, one of which is the El Niño Southern Oscillation (ENSO - Diaz et al., 2001), with well-documented climate response over subtropical regions including southern Africa (e,g, Dilley and Heyman, 1995) and implications for maize yields in South Africa (e.g. Cane et al., 1994, Moeletsi et al., 2011). Early applications for agriculture in this regard focussed purely on the climate response to ENSO to predict possible rainfall outcomes for a season and, with sufficient lead time, recommend strategies for fertilizer application and planting density accordingly. This approach has yielded positive results over areas where a strong ENSO influence has been reported such as the wheat belt over eastern Australia (Hammer et al., 1996), South Africa and Zimbabwe (Martin et al., 2000, de Jager et al., 1998) and is still being considered as useful information to be taken into account before planting in southern Africa (Zinyengere et al., 2011), Australia (Anwar et al., 2008; Everingham et al., 2008) and with application also in the USA (Cabrera et al., 2007). As 
South African summer rainfall is influenced, in addition to ENSO teleconnections, by other atmospheric circulation phenomena such as the Southern Annular Mode (Gillet, 2006) which is sensitive to more external forcing than only ENSO (Arblaster and Meehl, 2005). The exclusive use of ENSO as indicator for expected seasonal rainfall can present challenges. Anomalously wet conditions over large parts of the South African summer rainfall area during recent El Niño events such as during the 1997/98 (Landman and Beraki, 2012) and the 2009/10 summers substantiate the need to consider more than only the ENSO signal in explaining southern African summer rainfall variability.

In addition to focussing exclusively on the ENSO, advances in forecast skill demonstrated by Global Coupled Models (GCMs) could have potential benefits. GCMs have recently demonstrated the potential for useful application of their output towards forecasting the rainfall expected during a growing season with sufficient lead time for agricultural decision making for dryland agriculture in sub-humid and semi-arid regions such as northern Italy (Marletto et al., 2007), the wheat producing areas in Australia (Hansen et al., 2004, Asseng et al., 2012), Kenya (Hansen et al., 2009) and South Africa (Bezuidenhout and Schulze, 2006). The non-existence of crop yield data sometimes necessitates the use of crop growth models to simulate historical yield data (Roudier et al., 2012, Anwar et al., 2008, Hansen et al., 2009, Marletto et al., 2007) in order to develop and test a seasonal forecast model. Crop simulation models such as DSSAT (Decision Support System for Agrotechnology Transfer), and APSIM (McCown et al., 1995) are used to create such datasets. The gap in temporal and spatial resolution between climate data from statistical forecasts or GCM simulations and that used in crop simulation input models however necessitates the reference to so-called analogue years based on similarity to the current expected season (de Jager et al., 1998), application of stochastic weather generators (Semenov and Doblas-Reyes, 2007, Ines et al., 2011) or ensemble reordering of historical data (Ghile and Schulze, 2009). An alternative is to use historical yield data if available. Since technological advances and improvement in fertilizers and cultivars used are responsible for long-term trends in historical time series unrelated to climate variability, such data cannot be used in an original format. Trends are therefore removed by subtracting from the time series a low order mathematical model fitted to the time series (e.g. Hansen, 2004, Peiris et al., 2008).

South Africa is a net exporter of maize, the most important agricultural commodity produced for domestic consumption in the country. Crop cultivation (commercial, subsistence) is a land use that covers about $12 \%$ of the surface area of South Africa (Fairbanks et al., 2001). Commercial dryland cultivation of maize is by far the most prominent crop cultivation 


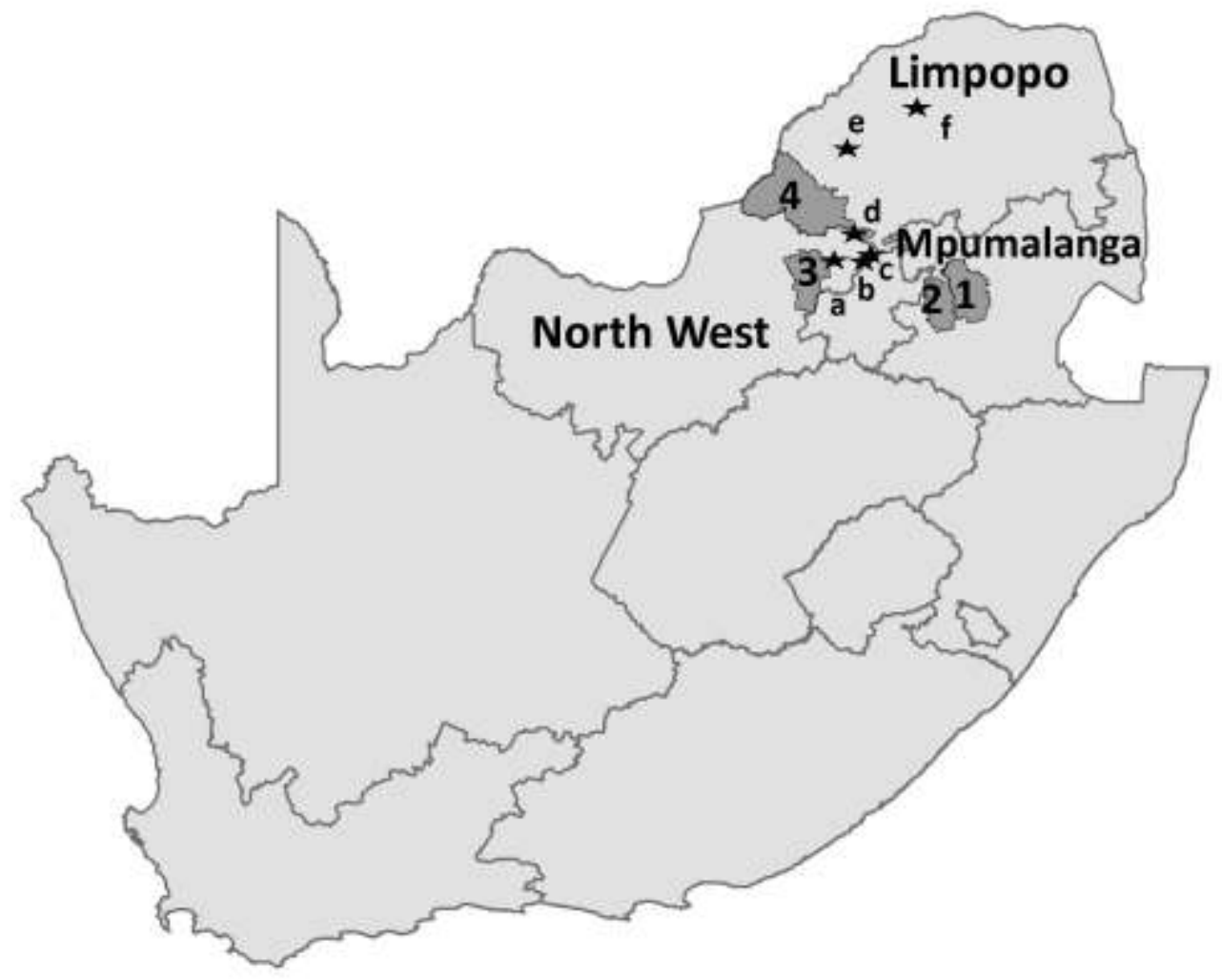

Figure 1. The Area of Intrerest. Relevant districts with maize production data used are: 1 - Middelburg, 2Witbank, 3 - Rustenburg, 4- Thabazimbi. The stream flow measuring points are: a - Beestkraal, b Krokodilpoort, c - Hartbeesfontein, d - Klipvoor, e- Dwaalhoek, f - Glen Alpine

category. The primary focus area for maize cultivation is the central to eastern parts of the country. Over the northeastern parts of South Africa (Northwest, Mpumalanga and the Limpopo Provinces - Figure 1), dryland cultivation covers between $10 \%$ and $15 \%$ of the area in the Northwest and Mpumalanga provinces where agricultural activity leans much more towards commercial agriculture than subsistence agriculture. The proportion of area where dryland cultivation is practiced over the Limpopo Province is about half of this with a 50/50 split in the commercial/subsistence proportions. Subsistence cultivation also contributes significantly to household nutrition in the area (Aliber and Hart, 2009).

Over the Limpopo Province there is also a greater proportion of irrigation as opposed to dryland cultivation relative to the other two provinces mentioned. The proportion of dryland cultivation decreases towards the northeast over this region due to increased unreliability of rainfall. The semi-arid nature of this region (Acocks, 1975, Peel et al., 2007, Mzezewa et al., 2010) makes inter-annual variability of rainfall a key aspect determining the success of agriculture similar to the situation in other semi-arid tropical regions of the world 
(Sivakumar, 1998) as water availability is a limiting factor for crop production. Concurrently, the management of water is one of the most crucial aspects of planning and risk assessments strategies in this region. From this perspective, the prediction of water resources is of great importance for irrigation fed crops. The statistical relationship between ENSO and streamflow in Southern Africa increases the potential for streamflow forecasting based partly on this association (Chiew and McMahon 2002). A strong relationship between streamflow and atmospheric variability over this area of South Africa in particular for the austral midsummer season was demonstrated (Landman et al., 2001) using the perfect prognosis technique (Wilks, 2011) applied to GCM atmospheric variables.

The high skill demonstrated over northeastern South Africa in forecasting the seasonal rainfall for Austral mid-summer (DJF) by November (Engelbrecht et al., 2011; Landman et al., 2012) and accumulated streamflow (Landman et el., 2009) through Model Output Statistics (MOS; Wilks, 2011) creates the opportunity for seasonal forecasts to be considered in agriculture during the decision making process relating to planting and other management strategies early in the growing season based on expected rainfall and subsequent potential yield and streamflow estimates. The timing of the forecast in November relative to the planting window for maize over these northeastern parts of South Africa (Dupisani, 1987, Sacks et al., 2010) renders this forecast useful. Rainfall during the DJF period over the region is of cardinal importance for the maize crop as it covers the period of tasseling and grain fill. In this paper we investigate the ability of a GCM to forecast an approximation of potential yield and streamflow by considering hindcasts of atmospheric circulation patterns for DJF made in November, downscaled to surface parameters, over a period of approximately three decades.

\section{Data and Methodology}

The area of interest (AOI) for this study is situated over the north-eastern interior of South Africa (Figure 1). Apart from high seasonal rainfall prediction skill during the austral midsummer, this area is also of particular interest in a joint project between South African and Japanese modellers through the Science and Technology Research Partnership for Sustainable Development (SATREPS). Since GCMs are performing well over this region, the assumption is made here that by skilfully modelling the climatic drivers (such as ENSO) responsible for describing the seasonal-to-interannual variability over the region, the models will also be able to provide forecast fields which can be used to predict variables strongly 
associated with rainfall such as dry-land crops and streamflow. However, ENSO is not the only climatic driver over South Africa captured by the physical global models: In a recent paper (Landman and Beraki, 2012) a statistical model that used only equatorial Pacific Ocean SST as predictor was used to retro-actively predict DJF rainfall over southern Africa. The skill of the statistical model was compared with skill obtained with a multi-model system consisting of coupled models of the DEMETER project (Palmer et al., 2004) and with the direct coupled version of the ECHAM4.5-MOM3 (DeWitt, 2005). The coupled models all outscored the statistical model, subsequently providing evidence that state-of-the-art physical models are superior to ENSO-based statistical models when predicting mid-summer rainfall over South Africa. Results obtained from the SINTEX-F system described here give a quantified example of the skill levels for crop yield and streamflow predictions achievable using a dynamical model plus MOS post-processing. We do not make a direct comparison with skill levels achievable from purely statistically based systems. However, as state-of-theart GCMs generally outperform statistical methods for DJF rainfall over the region (Landman et al., 2009, Landman and Beraki, 2012) we may expect, in general, that use of GCMs will provide more skilful predictions of crop yield and streamflow relative to purely statistical methods. Since the maize yields and streamflows over the region considered here are strong functions of rainfall during mid-summer, the same conclusion regarding which modelling system is preferred can be deduced for these derivatives of rainfall. Therefore, the prediction system discussed here is based on a physical global model only.

Crop yield data for Maize (White and Yellow) are obtained from the South African National Department of Agriculture, Directorate: Statistics and Economic Analysis. Yearly figures since the early 80's per district and per province are estimated from data assimilated from producers and other co-workers of the Department in the maize-producing areas of South Africa. The production figures are provided per district for white and yellow maize together and are representative of dryland agriculture. Irrigation cultivation comprises less than $10 \%$ of maize produced in South Africa and the influence of this should therefore be limited in the event of contamination of yield data for dryland cultivation. Considering the region of interest, we focus on the provincial figure for the Limpopo Province and also the figures for districts in close proximity to the southern border of Limpopo namely the Witbank and Middelburg Districts in Mpumalanga, the Rustenburg District in Northwest and the Thabazimbi District in Limpopo.

Streamflow data are obtained from the Hydrological Information System (HIS) (DWAF, 2012) of the Department of Water Affairs (DWAF). This system provides verified 
streamflow data for 22 drainage regions with multiple catchment flow-gauge data available for each drainage region. A comprehensive overview of flow-gauging structures in South African rivers is given in Wessels and Rooseboom, 2009. As the focus of this study is in the northeastern parts of South Africa, stations from the Limpopo drainage region are selected, serving as the basis for the predictability of streamflow. Stations are selected from the database on the basis of their data availability (to conform to the full model period) and the size of the catchment area. Data availability should exceed $90 \%$ throughout the study period to ensure proper representation of hydrological variation. This finally limits the number of stations used to 6 from a much larger initial set, mostly located over the north-western parts of the Limpopo Province. The six stations, approximate size of their catchments and average DJF streamflow are indicated in Table 1.

Table 1. Streamflow stations used in analysis.

\begin{tabular}{|c|c|c|c|c|}
\hline \multirow{2}{*}{ Flow Gauge Nr. } & River Name & Measuring Point & $\begin{array}{c}\text { Catchment Area } \\
\left(\mathrm{km}^{2}\right)\end{array}$ & $\begin{array}{c}\text { Average Flow for } \\
\text { DJF 1980-2010 } \\
\left(\text { Million } \mathrm{m}^{3}\right)\end{array}$ \\
\hline $\mathrm{A} 2 \mathrm{H} 019$ & Krokodil River & Beestkraal & 6131 & 34.5 \\
\hline $\mathrm{A} 2 \mathrm{H048}$ & Krokodil River & Krokodilpoort & 4691 & 29.4 \\
\hline $\mathrm{A} 2 \mathrm{H} 083$ & Krokodil River & Hartbeesfontein & 4116 & 18.7 \\
\hline $\mathrm{A} 2 \mathrm{H} 106$ & Pienaars River & Klipvoor & 6139 & 31.9 \\
\hline A4H005 & Mokolo River & Dwaalhoek & 6131 & 16.1 \\
\hline A6H029 & Mogalakwena & Glen Alpine & 11292 & 28.4 \\
\hline
\end{tabular}

The GCM data used in the study are from the archives of the Research Institute for Global Change (RIGC), formerly known as the Frontier Research Centre for Global Change of the Japan Agency for Marine-Earth Science and Technology (JAMSTEC). A number of studies has demonstrated the value of using $850 \mathrm{hPa}$ geopotential height fields from global models to predict seasonal rainfall variability over southern Africa (Engelbrecht et a., 2011; Landman and Goddard, 2002; Landman and Beraki, 2012; Landman et al., 2012); these height fields represent the low-level circulation over the larger part of the interior of southern Africa which is on average about $1.5 \mathrm{~km}$ above mean sea level. Here the $850 \mathrm{hPa}$ geopotential height hindcasts of the Scale Interaction Experiment-Frontier Research Centre for Global Change (FRCGC) coupled GCM (SINTEX-F) (Luo et al., 2005) are downscaled to the agricultural districts over north-eastern South Africa as well as to the gauging stations along the Limpopo 
drainage area. The SINTEX-F model consists of the T106L19 ECHAM-4.6 (Roeckner et al. 1996) atmospheric component, coupled to the ocean component Ocean Parallellise (OPA8.2, Madec et al. 1998), through the Ocean-Atmosphere-Sea Ice-Soil (OASIS 2.4, Valcke et al. 2000) coupler. Spatial resolution of the atmospheric component is approximately $1^{\circ} \mathrm{X} 1^{\circ}$ while the OPA 8.2 uses the Arakawa $\mathrm{C}$ grid with longitude-latitude resolution of $2^{\circ} \times 2^{\circ}$ cosine (latitude) with increased meridional resolution up to $0.5^{\circ}$ near the equator. The global model's hindcasts used were initialised in November for December to February (DJF) simulations at a 1-month lead-time over the 28-year period from 1983/84 to 2010/11, consisting of 9 ensemble members.

\section{Statistical downscaling using principal component regression:}

Biases in global model rainfall over southern Africa have been shown to be minimised through statistical post-processing (Landman and Goddard, 2002; Landman et al., 2009), and such processing also has as a result the production of forecast data directly applicable at a point of interest (Landman et al., 2012). Moreover, crop yields and streamflows are not represented explicitly by the global model, and so post-processing large-scale model output is warranted. The method used here to post-process SINTEX-F data to crop yields of certain agricultural district and streamflows from river flow-gauges is called model output statistics (MOS; Wilks, 2011). MOS equations are developed by using the principal component regression (PCR; Jolliffe, 2002) option of the Climate Predictability Tool (CPT) of the International Research Institute for Climate and Society (IRI; http://iri.columbia.edu). The maize yields over the selection of agricultural districts are first separately detrended by fitting a second-order polynomial to each series, selected on the basis of the respective $\mathrm{R}^{2}$ values of the fitted lines in order to resolve the time series. The second-order polynomial yields a higher $\mathrm{R}^{2}$ when fitted to the time series than a first-order polynomial. Both the resulting crop indices and streamflows are transformed into an approximate normal distribution prior to PCR. The DJF hindcast fields used in the MOS equations are restricted over a domain that covers an area between the equator and $80^{\circ} \mathrm{S}$ and from $20^{\circ} \mathrm{W}$ to $60^{\circ} \mathrm{E}$. This area is selected such that it will be able to capture the Southern Annular Mode (SAM; Gillett et al., 2006) and the high- and low-pressure systems over the sub-continent and over the southern Atlantic and Indian Oceans affecting southern African mid-summer rainfall variability (Tyson and Preston-Whyte, 2000). Principal component analysis (PCA) aims to reduce the dimensionality of a data set and in this case the 5041 grid-points of the $850 \mathrm{hPa}$ geopotential height fields over the area described above. PCR simply starts by applying PCA to the 
predictor $850 \mathrm{hPa}$ geopotential heights, thereby eliminating the possibility of multicollenearities in the model data and simplifying the regression calculations (Jolliffe, 2002). Here, the $850 \mathrm{hPa}$ height field have been reduced to 3 principle component time series used in the PCR.

The MOS equations' ability to produce skilful hindcasts is tested over the 28-year period using cross-validation with a large 5-year-out design, which means that 2 years on either side of the predicted year are omitted in order to minimise the artificial inflation of skill. Deterministic forecast skill is calculated for the 28-year cross-validation only by considering mean squared error skill scores and Kendall's tau (Wilks, 2011). The former is a relative accuracy measure (skill score) and with persistence used here as the reference hindcasts, while the Kendall's Tau (not unduly influenced by possible outlying data) is an alternative to the conventional Pearson correlation and has the additional attribute of discrimination (Jolliffe and Stephenson, 2011). In addition to cross-validation, the process of retro-active forecasting is applied over the 16-year period from 1995/96 to 2010/11 in order to produce a set of probabilistic downscaled hindcasts which are subsequently verified. A cross-validation 3 -year-out design is used for the retro-active process, and the initial cross-validation period of 12 years (1983/84 to 1994/95) is progressively increased by 1 year at each downscaled hindcast step. Owing to the small ensemble size of 9 members, the hindcasts distributions may be poorly sampled and so their uncertainties have to be estimated. Probabilistic hindcasts for the 16 years are subsequently obtained from the error variance of the 3-year-out crossvalidated hindcasts using the ensemble mean (Troccoli et al., 2008). These hindcasts are tested for discrimination (to determine if the hindcasts are discernibly different given different outcomes - for example, is the forecast probability for a bumper harvest systematically higher when the event occurs than when it does not occur?) and for reliability (to determine if the confidence communicated in the hindcasts is appropriate - for example, the hindcasts are considered reliable if there is consistency between the hindcast probabilities for high or low crop yields and the observed relative frequencies of the observed crop yields). For calculating the former as a verification measure, the relative operating characteristic (ROC; Mason and Graham, 2002) is used, and for the latter the reliability diagram (Hamill, 1997 ) is used. ROC curves (plotting the hindcast hit rates against the false alarm rates) are presented as well as their scores: If the area below the ROC curves is $\leq 0.5$, the model discriminates correctly only for less than half the time (Mason and Weigel, 2009). For a maximum ROC score of 1.0, perfect discrimination has been obtained. 


\section{Results}

The predictor field (SINTEX-F DJF $850 \mathrm{hPa}$ geopotential heights) used in the PCR is decomposed into spatial loading fields (Figure 2a) and time series representing independent climate modes of variation (Figure 2b). These modes emphasize the circulation patterns

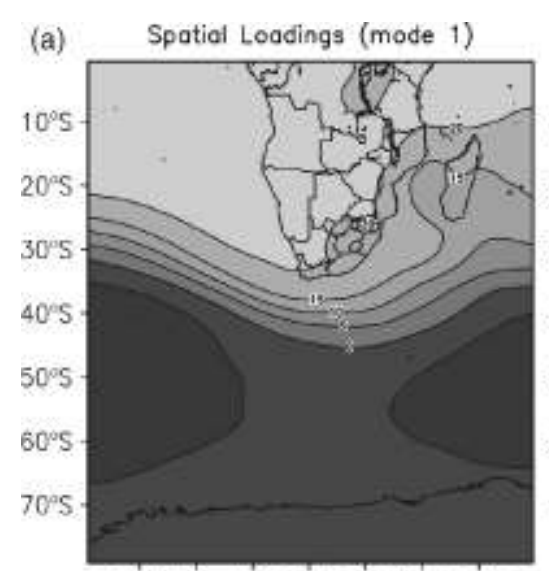

10\% 0 10 $10^{\circ} \mathrm{E} 20^{\circ} \mathrm{E} 30^{\circ} \mathrm{E} 40^{\circ} \mathrm{E} 50^{\circ} \mathrm{E}$

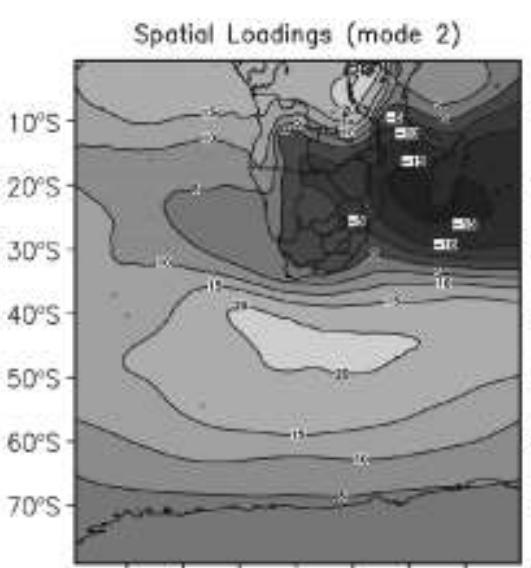

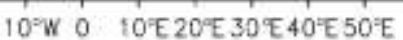

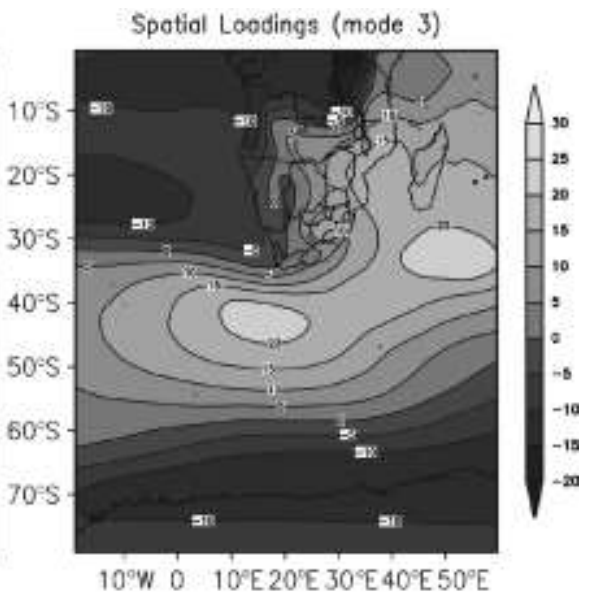

10\% 0 W $10^{\circ} \mathrm{E} 20^{\circ} \mathrm{E} 30^{\circ} \mathrm{E} 40^{\circ} \mathrm{E} 50^{\circ} \mathrm{E}$

(b)
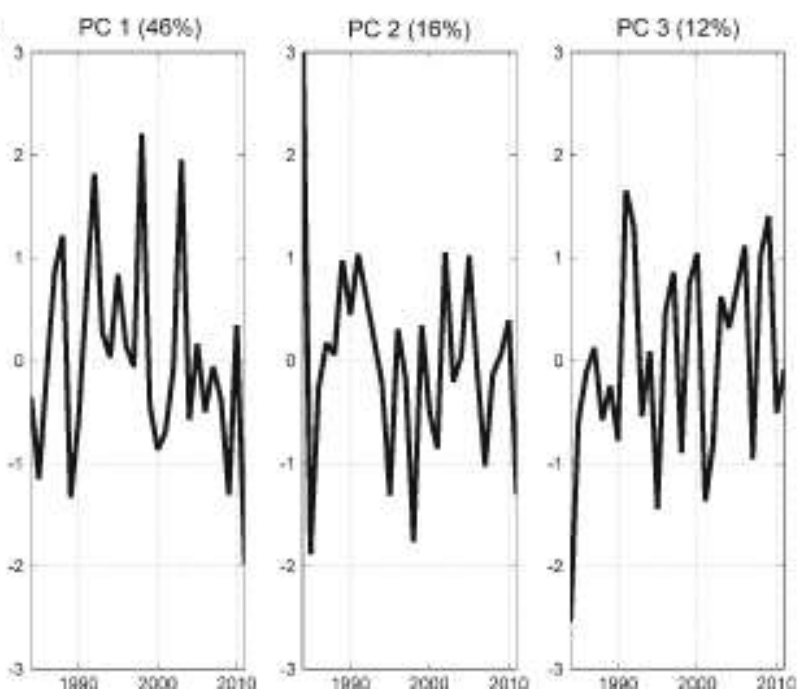

Figure 2. (a)The first three dominant PCA spatial loadings of the SINTEX-F's DJF $850 \mathrm{hPa}$ geopotential height field for the 28-year period of 1983/84 to 2010/11. (b) The temporal scores associated with the loadings (a). The explained variance of each mode is also presented

important for a rainfall signal over the area of interest and also their occurrence in time per DJF season. All three PCs show a response in terms of the Southern Annular Mode, to which rainfall over northeastern South Africa is positively correlated (Gillet, 2006), accentuated by relatively large contrasts between the areas south of $65^{\circ} \mathrm{S}$ and around $45^{\circ} \mathrm{S}$. The contrast in anomalies between areas towards the south of southern Africa and towards the north is 
emphasised in PC1. Positive anomalies towards the south and negative anomalies towards the north are associated with relatively wet conditions over the area of interest. PC 2 and 3 are also sensitive towards the position and strength of the Atlantic and Indian Ocean high pressure systems, but with particular emphasis towards the east of the country. Pressure anomalies towards the east of the country are thought to play an important role in mid to late summer rainfall over the northeastern parts of South Africa (Tyson, 1981, D'Abreton and Lindesay, 1993, Richard et al., 2001). Considering the semi-arid nature of the AOI and the sign of the anomalies represented by the PC fields, it is expected that PC1 should be negatively and the other two PC fields positively correlated to both yields and stream flow. Because of uncertainties in the forecastprocess seasonal forecasts are usually expressed probabilistically. Notwithstanding, it may be of interest to establish what the deterministic hindcast performance of a forecast system is. For this reason, the deterministic verification of crop yields downscaled from SINTEX-F ensemble mean hindcasts is presented here in terms of mean squared error skill scores (with persistence as reference forecast) and Kendall's tau, a rank correlation coefficient resistant to outliers. Persistence is considered a feasible reference hindcast here since farmers are often enquiring about the likelihood of either obtaining the same bumper yields of the previous season, or a repeat of a failed crop. Figure 3 shows the detrended crop yield anomalies (thick dashed lines) as a normalised index and the associated cross-validated (thin dashed lines) and retro-active (solid lines with crosses) hindcasts for four main agricultural districts which are predominantly associated with dryland maize production. The years on the graphs are representing the years in which the crops were harvested. Take note of the hindcast for each of the four districts for the 1998 harvest year. All of them, except for Thabazimbi, show the hindcast for that year well below the average, which was a year during which the rainfall forecast for the DJF 1997/98 El Niño season was for dry conditions to occur over the larger part of SADC south of about $10^{\circ} \mathrm{S}$ (Landman and Beraki, 2012; Landman et al., 2012). However, the rainfall forecast of an El Niño related drought to occur was over-confident and rainfall over the larger part of the summer rainfall regions of South Africa was observed to be near the average. The resulting close-to-average crop yields for all four districts in 1998 can be seen in Figure 3, even though the Thabazimbi hindcast was for an even bigger harvest. The discrepancy in the Thabazimbi forecast can be explained by the fact that the predictor time series, the principal component (PC) scores of the SINTEX-F $850 \mathrm{hPa}$ geopotential height fields, are uniquely related to the cross-validated crop yield hindcasts as seen in Table 2: While the sign of correlation values for all four districts is negative as expected considering the anomaly fields (Figure 2a) for 

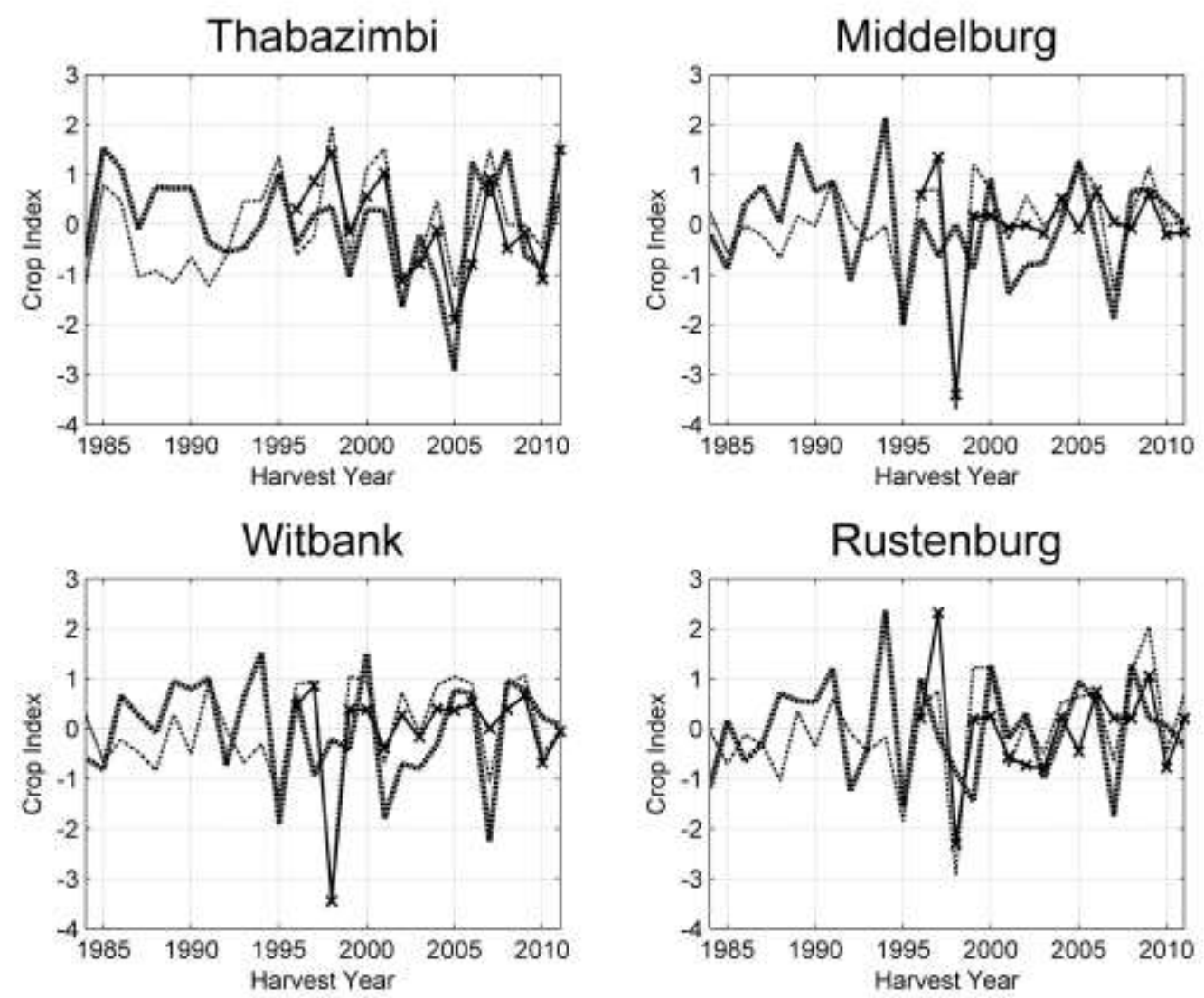

Figure 3. Observed (detrended, thick dashed lines) maize yield indices for four agricultural districts over northeastern South Africa, and associated cross-validated (thin dashed line) and retro-active (solid lines and crosses) downscaled hindcasts. The years indicated represent the year of harvesting

Table 2. Pearson correlations between PC 1 to 3 used in the PCR equations and the cross-validated crop yield hindcasts.

\begin{tabular}{|c|c|c|c|c|}
\hline & Thabazimbi & Middelburg & Witbank & Rustenburg \\
\hline PC 1 & -0.15 & -0.47 & -0.46 & -0.60 \\
\hline PC 2 & -0.82 & +0.56 & +0.52 & +0.38 \\
\hline PC 3 & -0.25 & +0.55 & +0.61 & +0.65 \\
\hline
\end{tabular}

PC 1, the sign of the correlation values for the Middelburg, Witbank and Rustenburg districts for PC 2 and for PC 3 is positive (also as expected), while for Thabazimbi it is the opposite, and the score of PC 1 for Thabazimbi is the lowest. The authors feel that this apparent discrepancy needs further clarification. The reason for the strong negative correlation value with PC2 at Thabazimbi may lie in contamination of yield data with irrigated cultivation figures as the total yield from dryland cultivation can be expected to be smaller here than at the other districts considered rendering the estimated production figure more vulnerable to be 
skewed by data from maize under irrigation. For example, the high yields during 2002/03 seems somewhat unrealistic, especially considering that the yields for that season was never again exceeded after that year, despite several subsequent seasons with above-normal rainfall. It can also be argued that the negative use of PC 2 emphasises the detrimental effects on rainfall that tropical cyclone activity towards the east of South Africa can have, especially further north in the region of interest, due to subsidence towards the west of the activity in the vicinity of the Mozambique Channel. Finally it also shows that spatial variation in rainfall on a seasonal scale as well as the occurrence of exceptional cases can influence findings based on statistical relationships, highlighting the importance of a longer historical time series. An El Niño related drought occurred over the larger part of South Africa during the 2006/07 seasons. Here the forecast for anomalously low yield is again only for the districts other than Thabazimbi, suggesting that the crops of that district seem to be associated with an opposite response to what is normally expected during El Niño seasons.

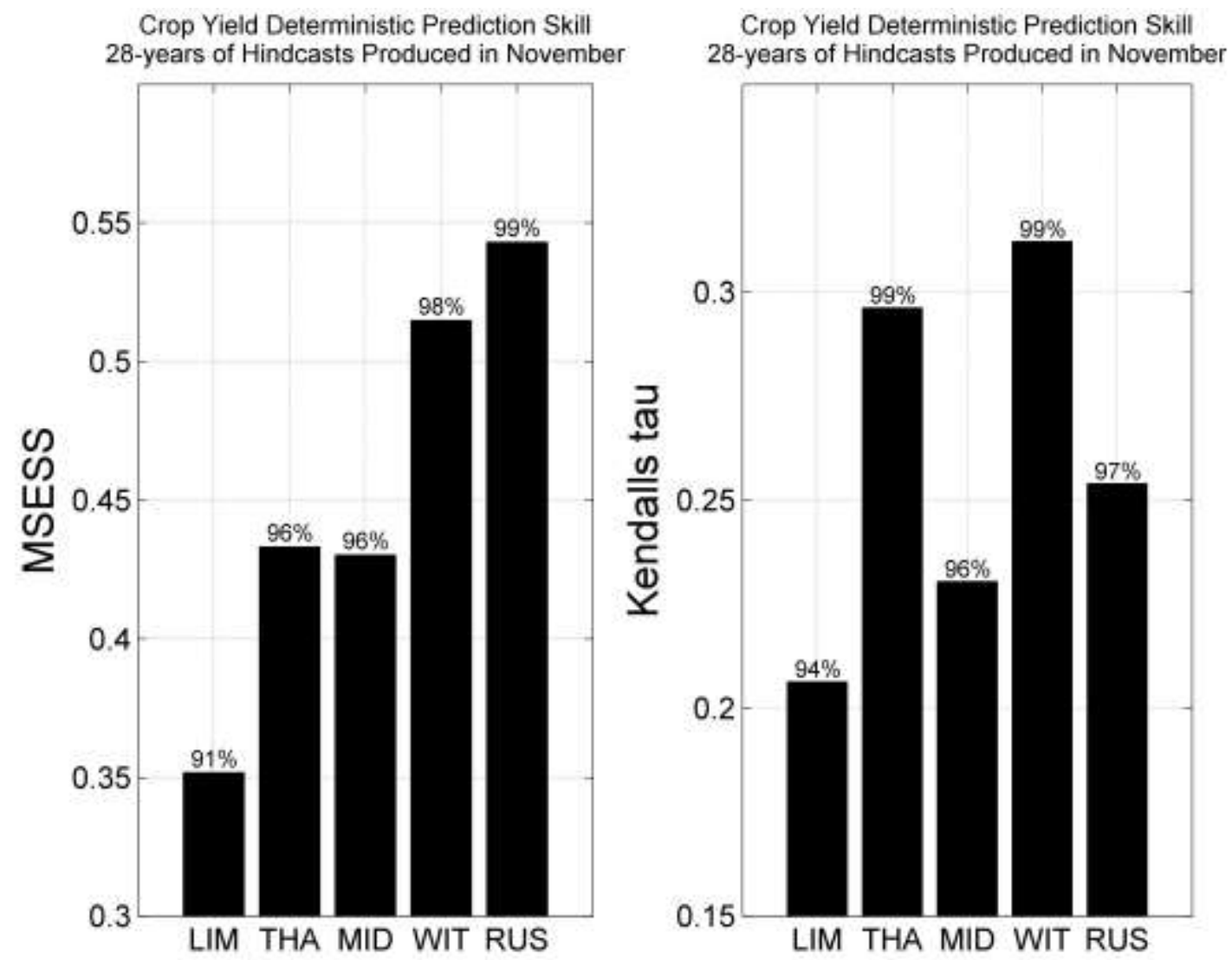

Figure 4. Mean squared error skill scores obtained by using persistence as reference hindcasts (left-hand panel) and Kendall's tau values (right-hand panel). The statistical significance for each score is shown on top of each bar. The significance values are obtained through a Monte Carlo rerandomization process 
The deterministic hindcast performance for each district is shown in Figure 4. In addition, verification scores for the Limpopo Province are also included. As a larger proportion of the final yield over the Limpopo Province is representative of irrigated crops, the provincial final crop yield estimate results could be influenced more significantly by occasional contamination from including both dry-land and irrigated crop data. The relatively low MSESS and Kendall's tau values for the province may therefore be a result of human influence in the form of irrigation that may negatively impact on the contribution from the climatic signal with which the physically based hindcasts of the global model is associated.

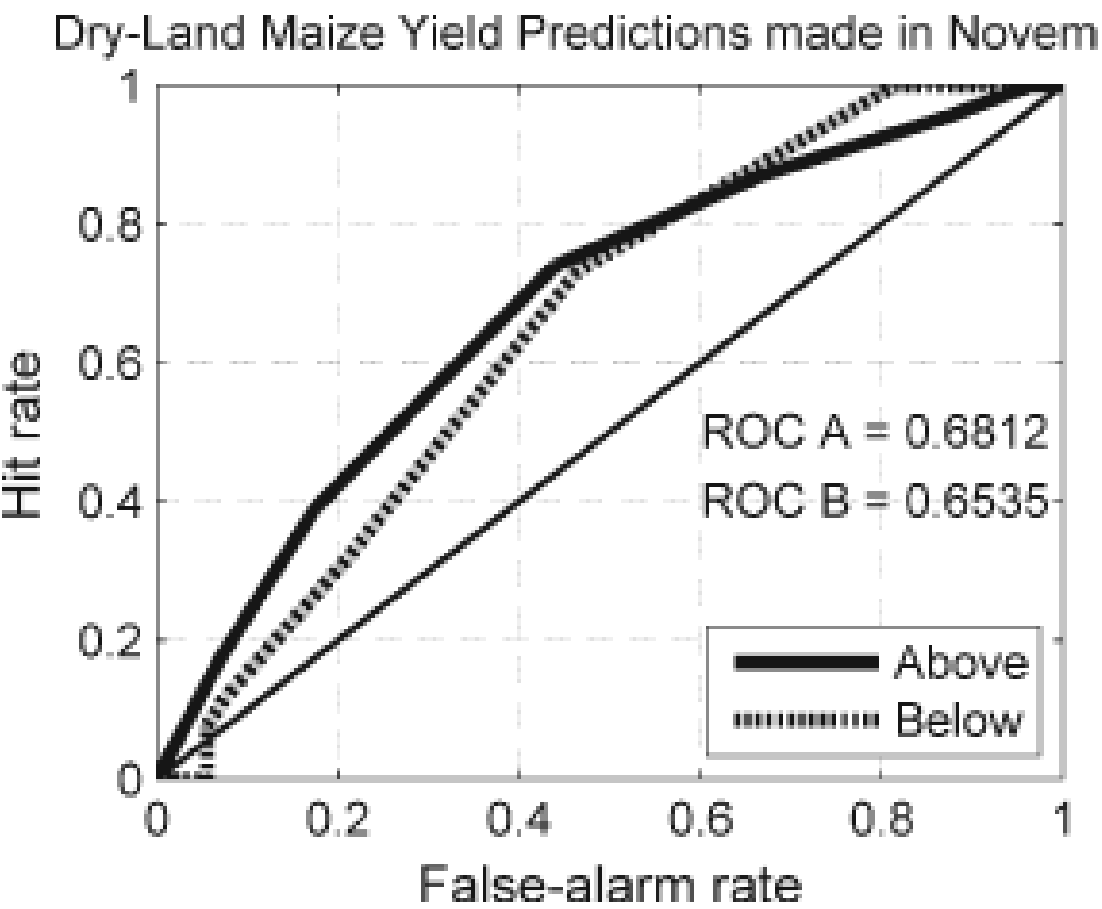

Figure 5. Relative operating characteristic curves for above- $\left(>67^{\text {th }}\right.$ percentile; thick solid curve) and below$\left(<33^{\text {rd }}\right.$ percentile; thick dashed curve $)$ normal maize yield hindcasts produced by downscaling SINTEX-F DJF $850 \mathrm{hPa}$ geopotential height fields to agricultural districts over north-eastern South Africa, and associated areas beneath each curve

The verification results of the 16-year probabilistic retro-active hindcasts for maize yield are presented in Figure 5 and 6. The downscaled hindcasts show good discrimination for both the low- and high-yield cases, with ROC scores for both categories $\sim 0.7$. The hindcasts also present a good level of reliability, but high-yield cases occur less frequently than anticipated by the prediction system, since the hindcast probabilities are consistently higher than the observed relative frequencies (the weighted least squares regression line is always below the diagonal line of perfect reliability). For seasonal climate forecasts, the most common situation is indicated by the weighted regression line for below-normal yields (Troccoli, 

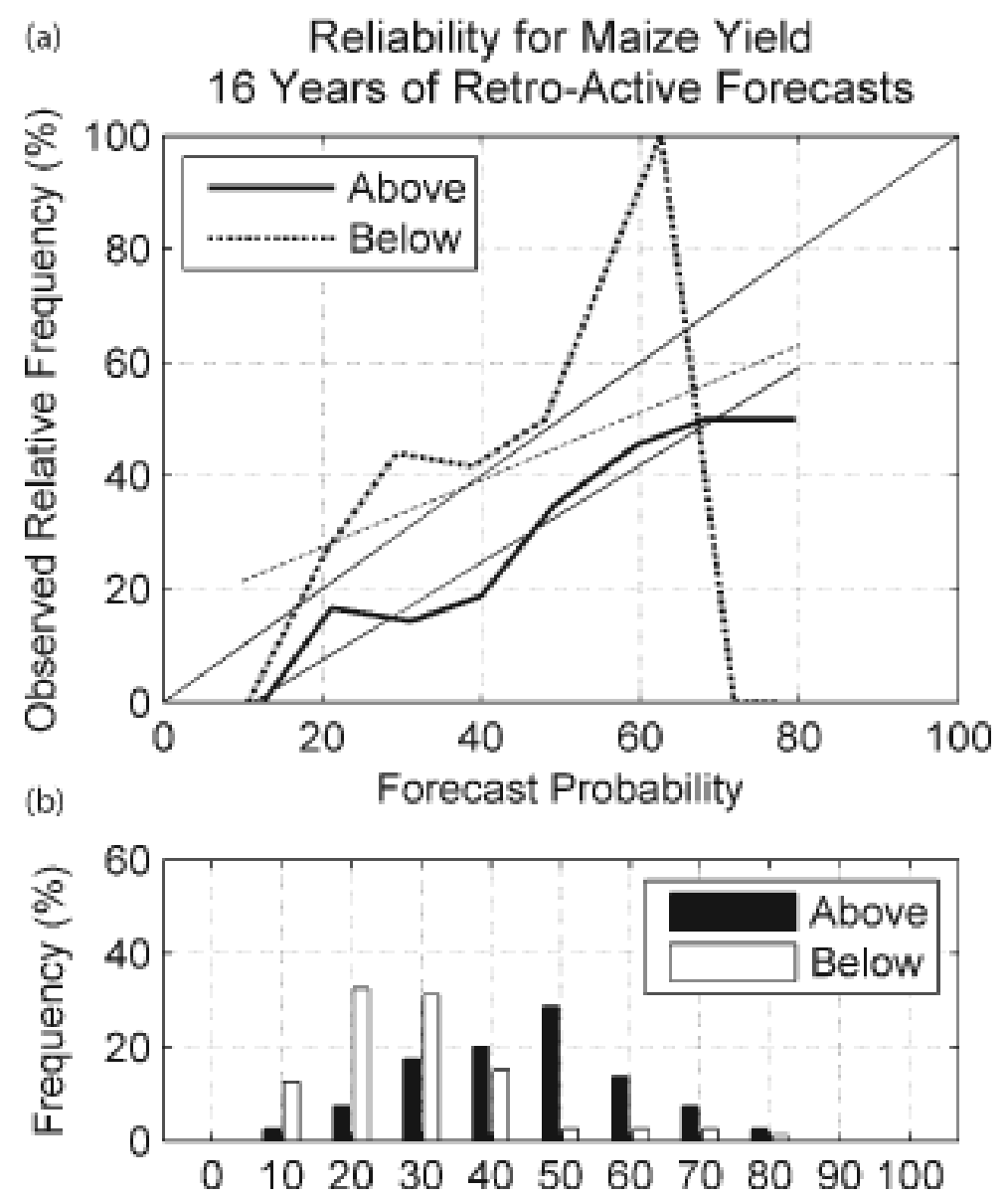

Figure 6. Reliability diagram (top) and frequency histogram (bottom) for above- $\left(>67^{\text {th }}\right.$ percentile) and below$\left(<33^{\text {rd }}\right.$ percentile) normal maize yield hindcasts produced by downscaling SINTEX-F DJF 850 hPa geopotential height fields to agricultural districts over north-eastern South Africa. The thick solid (dashed) curve and the black (white) bars represent the high- (low-) yield category. The thin solid (dashed) line is the weighted least squares regression line of the high- (low-) yield reliability curve

2008). Here the hindcasts correctly indicate increases as well as decreases in the probabilities of low-yield years, but the changes in probabilities are over-stated, giving rise to a slope of less than $45^{\circ}$, indicating that the hindcasts for low-yields are over-confident. The histograms below the reliability diagram of Figure 6 show the frequencies with which high-yield and low-yield hindcasts respectively occur in probability intervals of $10 \%$, and shows how strongly and how often the hindcast probabilities depart from the climatological probabilities (33\% for the three equi-probable case presented here - high- (low-) yield seasons are associated with the top (bottom) 33\% of climatology). Ideally, the hindcasts should have frequencies of probabilities close to $0 \%$ and $100 \%$ in which case the histogram would be ushaped as opposed to the inverted v-shaped histogram seen here. Notwithstanding. the hindcasts possess some sharpness (the level of confidence that is communicated in the hindcasts) since there are hindcasts obtained here with probabilities across most of the range. 
However, the low-yield cases are more "peaked" around 33\% indicating that most of the hindcasts have probabilities close to the climate frequency - so hindcasts for this category are less sharp than those for the high-yield cases (Figure 6).

The verification results presented thus far are mainly for rain-fed agricultural production. Judging by both the deterministic and the probabilistic verification results, operational prediction of maize-yield can be skilfully attempted over north-eastern South Africa by using the technique presented here of downscaling the large-scale circulation of a global model to observed yields. This notion signifies progress towards the estimation of crops based on objective, verifiable predictions systems such as the one presented here. Notwithstanding, the presented prediction system produce hindcasts with reduced skill for districts where irrigation is practiced more widely (e.g. lower skill for the Limpopo province).The maize estimation for irrigated crops prior to the rainy season therefore cannot be served by the presented prediction system.

An alternative approach to help irrigation farmers with planning for a coming season could be one that predicts the seasonal flows within the drainage area from which they obtain their water supply for irrigation. The same predictor field (DJF $850 \mathrm{hPa}$ geopotential heights produced by the SINTEX-F coupled model) is used to predict for the flows as measured at six flow-gauges within the Limpopo drainage area. The probabilistic hindcasts for streamflows, similarly produced and for the same period of 16 seasons as was done for the maize yields presented above, are also verified here in order to determine if an operational prediction system for streamflows is feasible. Figures 7 and 8 show probabilistic verification results of the streamflow hindcasts. ROC scores well above 0.5 are found here, suggesting, as in the case for maize yield, that the streamflow forecast system is able to discriminate low-level flows from the rest of the flows, as well as high-level flows from the rest of the flows (Figure 7). However, the reliability shown in Figure 8 seems to be lower than for the maize yield case shown in Figure 6. For low-level flows specifically (as opposed to low crop yields) the 16-year hindcasts are generally over-confident (Wilks, 2011). The hindcast probabilities of the high-level flows are consistently lower than the observed relative frequencies, which 


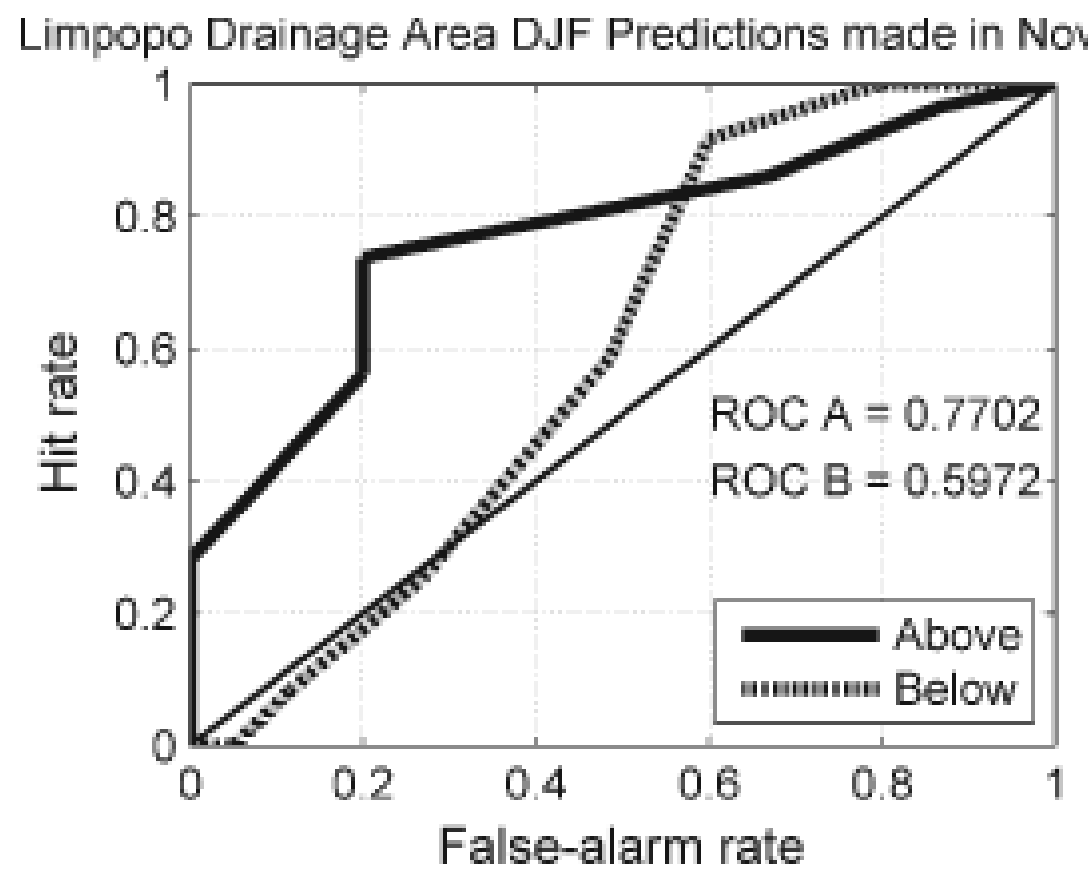

Figure 7. Relative operating characteristic curves for above- $\left(>67^{\text {th }}\right.$ percentile; thick solid curve) and below$\left(<33^{\text {rd }}\right.$ percentile; thick dashed curve) normal streamflows of the Limpopo drainage area hindcasts produced by downscaling SINTEX-F DJF $850 \mathrm{hPa}$ geopotential height fields to six flow-gauges, and associated areas beneath each curve
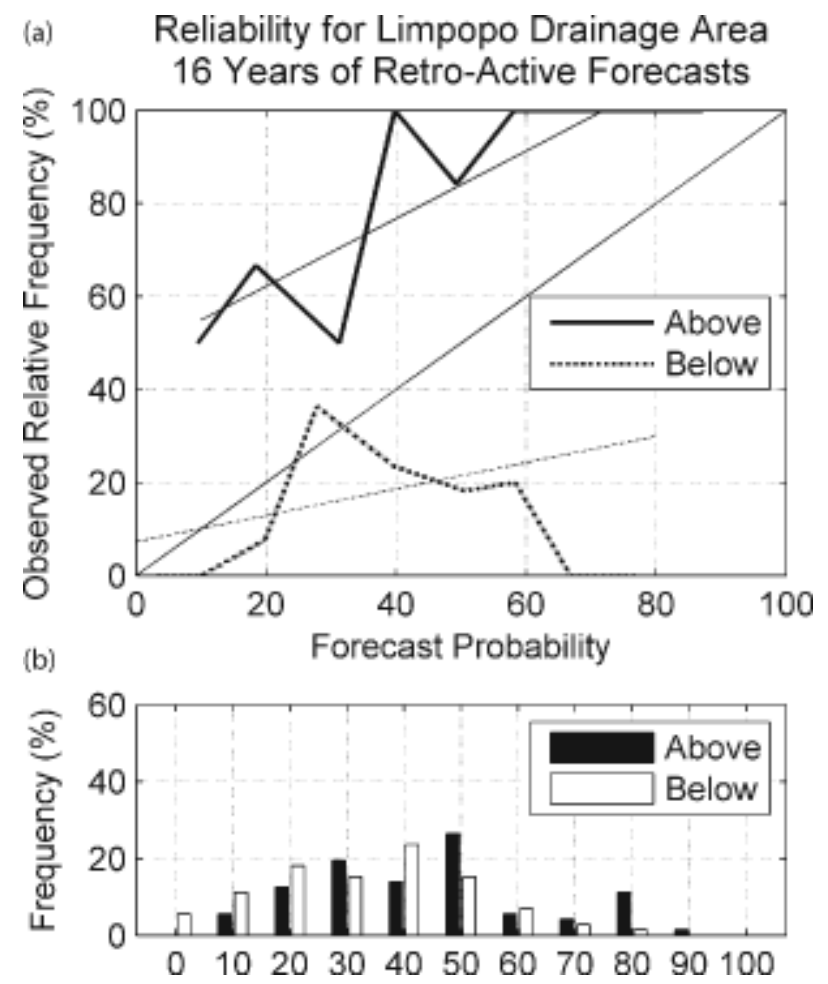

Figure 8. Reliability diagram (top) and frequency histogram (bottom) for above- $\left(>67^{\text {th }}\right.$ percentile) and below$\left(<33^{\text {rd }}\right.$ percentile) normal streamflows of the Limpopo drainage area hindcasts produced by downscaling SINTEX-F DJF $850 \mathrm{hPa}$ geopotential height fields to six flow-gauges. The thick solid (dashed) curve and the black (white) bars represent the high- (low-) yield category. The thin solid (dashed) line is the weighted least squares regression line of the high- (low-) yield reliability curve 
indicate that high-level flows always occur more frequently than predicted by the forecast system. These verification results suggest that irrigation-based maize producers may benefit from using operational streamflow forecasts, but that they may be best advised to use such forecasts with caution owing to the low reliability shown here. Notwithstanding, the system should be able to supply forecast information with good high-flow discrimination that could improve on crop estimates for farmers using irrigation as a water source for optimising maize production.

\section{Discussion and Conclusions}

The use of a coupled ocean-atmosphere model's large-scale output to predict end-of-season maize yield and mid-summer seasonal streamflows over north-eastern South Africa was investigated. Re-forecasts or hindcasts of DJF $850 \mathrm{hPa}$ geopotential height fields were statistically downscaled respectively to yields at four agricultural districts and to flows at six river flow-gauges. The main reason for this modelling study was to investigate the feasibility to construct operational forecast systems which are both objective and verifiable and can be used to help reduce the risk in agricultural decision-making. The forecast systems are objective since they consist of a regression-based approach which uses the three most dominant climatological modes of the coupled model's low-level circulation as predictors, all of which have a physical basis which is recognised as synoptic patterns likely to contribute to a robust description of the seasonal-to-interannual variability over southern Africa during the austral mid-summer. The systems are also verifiable since a set of downscaled hindcasts were created through a procedure that mimics a true operational forecasting environment. Verification of the downscaled hindcasts shows that the prediction systems work well under certain conditions. For example, dry-land crops have a better chance of being predicted reliably than irrigation conditioned crops. Moreover, good discrimination is obtained for both crops and streamflow hindcasts, but often associated with over-confidence. High maize yields occur less frequently than predicted, and for streamflow, high flows occur more frequently than predicted. Notwithstanding the discrepancies identified in the forecast systems, these types of seasonal forecasts are generally lacking in South Africa, and so the provision of modestly skilful forecasts on a real-time operational basis, and even at the relatively short 1month lead-time presented here, may benefit both dry-land and irrigation farmers, agricultural economists, seed companies, farming co-operations, to name but a few. 
Notwithstanding the establishment of new regression-based technologies for objective crop prediction in South Africa, more sophisticated methods to model crops remain warranted. The results presented here may also be considered as a baseline that needs to be outscored by more sophisticated approaches. Examples of such approaches include the use of physical crop models that assimilate output from global climate models on temporal and spatial scales reconcilable with their requirements (e.g. Le Roux, 2009). These crop models can only perform well if the output from global model systems is skilfully representing reality. Improvement and development of global forecasting systems over southern Africa has already been demonstrated through multi-model ensembles (Landman and Beraki, 2012), ocean-atmosphere coupled models (Landman et al., 2012) and the development of coupled model systems in South Africa (Beraki et al., 2011; Engelbrecht et al., 2010). These global modelling systems should further enhance seasonal forecast skill over southern Africa and subsequently help improve empirically based systems such as those presented in this paper. Implementing and using these objective and verifiable MOS models operationally will be a first for South Africa.

\section{Acknowledgements:}

The research on which the paper is based is supported by SATREPS and by ACCESS. SATREPS (Science and Technology Research Partnership for Sustainable Development) is a program for research projects by the Japan Science and Technology Agency (JST) and the Japan International Cooperation Agency (JICA). ACCESS (Applied Centre for Climate and Earth System Science) is a South African Centre of Excellence of the Department of Science and Technology.

The Authors would also like to thank the two anonymous reviewers for their contributions towards substantially improving the paper.

\section{REFERENCES}

Acocks JPH. 1975. Veld types of South Africa ( $2^{\text {nd }}$ edn). Memoirs of the botanical Survey of South Africa 40, Government Printer, Pretoria.

Aliber M and Hart TGB. 2009. Should subsistence agriculture be supported as a strategy to address rural food security? Agrekon: Agricultural Economics Research, Policy and Practice in southern Africa 48(4): 434-458. 
Anwar MR, Rodriguez D, Liu DL, Power S and O’Leary GJ. 2008. Quality and potential utility of ENSO-based forecasts of spring rainfall and wheat yield in south-eastern Australia. Aust J Agr Res 59: 112-126. Doi: 10.1071/AR07061

Arblaster JM and Meehl GA. 2005. Contributions of external forcings to Southern Annular Mode trends. J Climate 19: 2896-2905.

Archer ERM. 2003. Identifying Underserved End-User Groups in the Provision of Climate Information. B Am Meteorol Soc 84: 1525-1532. Doi: 10.1175/BAMS-84-11-1525

Asseng S, McIntosh PC, Wang G and Khimashia N. 2012. Optimal N fertiliser management based on a seasonal forecast. Eur J Agron 38: 66-73. Doi:10.1016/j.eja.2011.12.005.

Beraki A, DeWitt D, Landman WA and Olivier C. 2011. Ocean-atmosphere coupled climate model development at SAWS: Description and diagnosis. South African Society for Atmospheric Sciences 27th Annual Conference, 22-23 September 1011, Hartbeespoort, North-West Province, South Africa. ISBN 978-0-620-50849-0.

Bezuidenhout C N and Schulze RE. 2006. Application of seasonal climate outlooks to forecast sugarcane production in South Africa. Clim Res 30: 239 - 246.

Cabrera, VE; Jagtap SS and Hildebrand PE. 2007. Strategies to limit (minimize) nitrogen leaching on dairy farms driven by seasonal climate forecasts. Agr Ecosyst Environ 122: $479-489$.

Cane MA, Eschel G and Buckland RW.1994. Forecasting Zimbabwe maize yield using Eastern Equatorial Pacific sea surface temperature. Nature 370: 204-205.

Chiew FHS and McMahon TA. 2002. Global ENSO-streamflow teleconnection, streamflow forecasting and interannual variability. Hydrolog Sci J 47: 505-522.

de Jager JM,Potgieter AB and van den Berg WJ. 1998. Framework for forecasting the extent and severity of drought in maize in the Free State Province of South Africa. Agr Syst 57(3): 351-365.Doi:10.1016/S0308-521X(98)00023-7.

Department of Water Affairs. 2012. Hydrological Services, viewed August 18-29 2012, http://www.dwaf.gov.za/hydrology/

DeWitt DG. 2005. Retrospective forecasts of interannual sea surface temperature anomalies from 1982 to present using a directly coupled atmosphere-ocean general circulation model. Mon Weather Rev 133: 2972-2995. 
Diaz HF, Hoerling MP and Eischeid JK. 2001. ENSO variability, teleconnections and climate change. Int J Climatol 21: 1845-1862.

Dilley M and Heyman BN. 1995. ENSO and disaster: Droughts, floods and El Niño. Disasters 19(3): 181-193.

Du Pisani A. 1987. The CERES-Maize model as potential tool for drought assessment in South Africa. Water SA 13(3): 159 - 164.

Engelbrecht FA, Landman WA, Engelbrecht CJ, Landman S, Bopape, MM, Roux B, McGregor JL and Thatcher M. 2011. Multi-scale climate modelling over southern Africa using a variable-resolution global model. Water SA 37: 647-658.

Engelbrecht, F., McGregor, J. and Tsugawa, M. 2010. On the development of a new cubebased coupled climate model: Geometric aspects. South African Society for Atmospheric Sciences 27th Annual Conference, 22-23 September 2011, Hartbeespoort, North-West Province, South Africa. ISBN 978-0-620-50849-0.

Everingham YL, Clarke A J and Van Gorder S. 2008. Long lead rainfall forecasts for the Australian sugar industry. Int J Climatol 28: 111-117. Doi: 10.1002/joc.1513 Fairbanks DHK, Thompson MW, Vink DE, Newby TS, van den Berg HM and Everard DA. 2000. The South African land-cover characteristics database: a synopsis of the landscape. S Afr J Sci 96: 69-82.

Ghile YB and Schulze RE. 2009. Use of an ensemble re-ordering method for disaggregation of seasonal categorical rainfall forecasts into conditioned ensembles of daily rainfall for hydrological forecasting. J Hydrol 371: 85-97.Doi: 10.1016/j.jhydrol.2009.03.019.

Gillet NP, Kell TD and Jones PD. 2006. Regional climate impacts of the Southern Annular Mode. Geophys Res Lett 33: L23704. Doi:10.1029/2006GL027721

Hamill T. 1997. Reliability diagrams for multicategory probabilistic forecasts. Weather Forecast 12: 736-741.

Hammer GL, Holzworth DP and Stone R. 1996. The value of skill in seasonal climate forecasting to wheat crop management in a region with high climatic variability. Aust J Agr Res 47: 717-737. Doi:10.1071/AR9960717

Hansen JW, Mason SJ, Sun L and Tall A. 2011. Review of seasonal climate forecasting in sub-Saharan Africa. Exp Agr 47: 205-240. 
Hansen JW, Mishra A, Rao KPC, Indeje M and Ngugi RK. 2009. Potential value of GCMbased seasonal rainfall forecasts for maize management in semi-arid Kenya. Agr Syst 101 (1-2): 80-90. Doi:10.1016/j.agsy.2009.03.005.

Hansen JW, Potgieter A and Tippett MK. 2004. Using a general circulation model to forecast regional wheat yields in northeast Australia. Agr Forest Meteorol 127(1-2): 77-92. Doi:10.1016/j.agrformet.2004.07.005.

Hayman P, Crean J, Mullen J and Parton K. 2007. How do probabilistic seasonal climate forecasts compare with other innovations that Australian farmers are encouraged to adopt? Aust J Agr Res 58: 975-984.

Ines AVM, Hansen JW and Robertson AW. 2011. Enhancing the utility of daily GCM rainfall for crop yield prediction. Int J Climatol 31: 2168-2182.

Doi: $10.1002 /$ joc. 2223

Jolliffe IT. 2002. Principal Component Analysis, Second Edition. Springer, New York. Jolliffe, IT and Stephenson DB. 2011. Forecast Verification: A Practitioner's Guide in Atmospheric Sciences, Second Edition. Wiley, Amsterdam.

Klopper E, Vogel CH and Landman WA. 2006. Seasonal climate forecasts - potential agricultural-risk management tools? Climatic Change 76: 73-90.

Klopper E. 1999. The use of seasonal forecasts in South Africa during the 1997/98 rainfall season. Water SA 25: 311-316.

Landman W.A. and Beraki, A. 2012. Multi-model forecast skill for midsummer rainfall over southern Africa. Int J Climatol 32: 303-314. Doi: 10.1002/joc.2273.

Landman WA, and Goddard L. 2002. Statistical recalibration of GCM forecasts over southern Africa using model output statistics. J Climate 15: 2038-2055.

Landman WA, DeWitt D, Lee D-E, Beraki, A and Lötter D. 2012. Seasonal rainfall prediction skill over South Africa: 1- vs. 2-tiered forecasting systems. Weather Forecast 27: 489-501. Doi: 10.1175/WAF-D-11-00078.1.

Landman WA, Engelbrecht FA, Beraki A, Engelbrecht C, Mbedzi M, Gill T and Ntsangwane L. 2009. Model Output Statistics Applied to Multi-Model Ensemble Long-Range Forecasts over South Africa. WRC Report No. 1492/1/08. Water Research Commission, Pretoria, South Africa. 56 pp 
Landman WA, Kgatuke MM, Mbedzi, M, Beraki A, Bartman A and du Piesanie A. 2009. Performance comparison of some dynamical and empirical downscaling methods for South Africa from a seasonal climate modelling perspective. Int J Climatol 29: 15351549. Doi: 10.1002/joc. 1766.

Landman WA, Mason SJ, Tyson PD and Tennant WJ. 2001. Statistical downscaling of GCM simulations to Streamflow. J Hydrol 252(1-4): 221-236. Doi:10.1016/S00221694(01)00457-7

Le Roux N. 2009. Seasonal maize yield simulations for South Africa using a multi-model ensemble system. Unpublished MSc dissertation, University of Pretoria.

Luo JJ, Masson S, Behera S, Shingu S and Yamagata T. 2005. Seasonal climate predictability in a coupled OAGCM using a different approach for ensemble forecasts. J Climate 18: 4474-4497.

Madec G, Delecluse P, Imbard M, and Levy C. 1998. OPA 8.1 ocean general circulation model reference manual. LODYC/IPSL Tech. Rep. Note 11, 91 pp.

Marletto V,Ventura F, Fontana G and Tomei F. 2007. Wheat growth simulation and yield prediction with seasonal forecasts and a numerical model, Agr Forest Meteorol 147(1-2): 71-79. Doi:10.1016/j.agrformet.2007.07.003.

Martin RV, Washington R and Downing TE. 2000. Seasonal Maize Forecasting for South Africa and Zimbabwe Derived from an Agroclimatological Model. J Appl Meteorol 39:1473-1479. Doi: 10.1175/1520-0450(2000)039<1473:SMFFSA>2.0.CO;2

Mason SJ and Graham NE. 2002. Areas beneath the relative operating characteristics (ROC) and relative operating levels (ROL) curves: Statistical significance and interpretation. Q J Roy Meteorol Soc 128: 2145-2166.

Mason SJ and Weigel AP. 2009. A Generic Forecast Verification Framework for Administrative Purposes. Mon Wea Rev 137: 331-349. Doi: 10.1175/2008MWR2553.1

McCown RL, Hammer GL, Hargreaves JNG, Holzworth D and Huth NI. 1995. APSIM: an agricultural production system simulation model for operational research. Math Compute Simulat 39: 225-231. 
Moeletsi ME, Walker S and Landman LA. 2011. ENSO and implications on rainfall characteristics with reference to maize production in the Free State Province of South Africa. Phys Chem Earth (A/B/C) 36: 715-726.Doi: 10.1016/j.pce.2011.07.043.

Mzezewa J, Misi T and van Rensburg LD. 2010. Characterisation of rainfall at a semi-arid ecotope in the Limpopo Province (South Africa) and its implications for sustainable crop production. Water SA 36(1): 19-26.

O'Brien K and Vogel C (eds.) 2003. Coping with climate variability. The use of seasonal climate forecasts in southern Africa. Ashgate Studies in Environmental Policy and Practice, Hampshire, England.

Palmer TN, Alessandri A, Andersen U, Cantelaube P, Davey M, Delecluse P, Deque M, Diez E, Doblas-Reyes FJ, Feddersen H, Graham R, Gualdi S, Gueremy JF, Hagedorn R, Hoshen M, Keenlyside N, Latif M, Lazar A, Maisonnave E, Marletto V, Morse AP, Orfila B, Rogel P, Terres JM, Thomson MC. 2004. Development of a European multimodel ensemble system for seasonal-to-interannual prediction (DEMETER). $B$ Am Meteorol Soc 85: 853-872.

Peel MC, Finlayson BL and McMahon TA. 2007. Updated world map of the Köppen-Geiger climate classification, Hydrology and Earth System Science. 11: 1633-1644, Doi:10.5194/hess-11-1633-2007.

Peiris TSG, Hansen JW and Zubair L. 2008. Use of seasonal climate information to predict coconut production in Sri Lanka. Int J Climatol 28: 103-110. Doi: 10.1002/joc.1517.

Roeckner E, Bäuml G, Bonaventura L, Brokopf R, Esch M, Giorgetta M, Hagemann S, Kirchner I, Kornblueh L, Manzini E, Rhodin A, Schlese U, Schulzweida U and Tompkins A. 1996. The atmospheric general circulation model ECHAM4: Model description and simulation of present day climate. Max-Plank-Institute für Meteorologie Rep. 218, Hamburg, Germany, 90 pp.

Roudier P, Sultan B, Quirion P, Baron C, Alhassane A, Traoré S B and Muller B. 2012. An ex-ante evaluation of the use of seasonal climate forecasts for millet growers in $\mathrm{SW}$ Niger. Int J Climatol 32: 759-771. Doi: 10.1002/joc.2308

Sacks WJ, Deryng D, Foley JA and Ramankutty N. 2010. Crop planting dates: an analysis of global patterns. Global Ecology and Biogeography 19: 607-620. Doi: 10.1111/j.14668238.2010.00551.x 
Semenov MA and Doblas-Reyes FJ. 2007. Utility of dynamical seasonal forecasts in predicting crop yield. Clim Res 34:71-81. Doi: 10.3354/cr034071

Sivakumar MVK. 1998. Climate variability and food vulnerability. Global Change Newsletter (IGBP) 35: 14-17.

Troccoli, A., Harrison, M., Anderson, D.L.T. and Mason S.J. 2008. Seasonal Climate: Forecasting and Managing Risk. NATO Science Series on Earth and Environmental Sciences, Vol 82. Springer, New York.

Tyson PD and Preston-Whyte RA. 2000. The Weather and Climate of Southern Africa. Oxford University Press, Cape Town.

Tyson PD. 1981. Atmospheric circulation variations and the occurrence of extended wet and dry spells over Southern Africa. J Climatol 1: 115-130.

Valcke S, Terray L, and Piacentini A. 2000. The OASIS coupler using guide version 2.4. Tech. Rep. TR/CMGC/00-10. CERFACS, Toulouse, France, 85pp.

Vogel C and O'Brien K. 2006. Who can eat information? Examining the effectiveness of seasonal climate forecasts and regional climate-risk management strategies. Clim Res 33: $111-122$.

Wessels P. and Rooseboom A. 2009. Flow-Gauging Structures in South African Rivers. Water SA 35(1): 1-19.

Wilks DS. 2011. Statistical Methods in the Atmospheric Sciences, Third Edition. Academic Press, Amsterdam.

Ziervogel G. 2004. Targeting seasonal climate forecasts for integration into household level decisions: the case of smallholder farmers in Lesotho. Geogr J 170: 6-21. Doi: 10.1111/j.0016-7398.2004.05002.x

Zinyengere N, Mhizha T, Mashonjowa E,Chipindu B, Geerts S and Raes D. 2011. Using seasonal climate forecasts to improve maize production decision support in Zimbabwe. Agr Forest Meteorol 151(12): 1792-1799.

Doi:10.1016/j.agrformet.2011.07.015. 